ISSN 0103-9954

\title{
ESTIMATIVAS DE PARÂMETROS GENÉTICOS PARA CARACTERES DE FRUTOS EM AÇAIZEIROS NO AMAPÁ
}

\author{
PARAMETER ESTIMATES FOR GENETIC CHARACTERS OF ASSAI PALM TREES FRUITS IN \\ AMAPÁ STATE
}

Gilberto Ken-Iti Yokomizo ${ }^{1}$ Silas Mochiutti ${ }^{2}$ José Antônio Leite de Queiroz ${ }^{3}$ George Reis dos Santos ${ }^{4}$ Renan Gomes Furtado ${ }^{4}$ Ancelma Pereira Brandão ${ }^{5}$ Irecê Bezerra Colares ${ }^{5}$

\section{RESUMO}

Com o objetivo de estimar a variabilidade genética e ganhos de seleção em caracteres de frutos em açaizeiros, foram avaliadas 68 progênies provenientes de coleta em populações do município de Afuá e instaladas no Amapá. O experimento foi instalado em blocos ao acaso com duas repetições e quatro plantas úteis por parcela. Foram avaliados os caracteres: diâmetro longitudinal do fruto (DLF); maior diâmetro transversal do fruto (DTMA); menor diâmetro transversal do fruto (DTME); massa de cem frutos (P100) e massa total de frutos no cacho (PTC). Há diferenças significativas entre progênies, o que denota possibilidade de ganhos com a seleção. Em geral, as herdabilidades na média de progênies foram de médias a altas para os caracteres, mas sempre menor para PTC. A relação $\mathrm{CVg} / \mathrm{CVe}$ foi favorável em DMA e DTME e desfavorável para PTC; as correlações entre os caracteres foram positivas e significativas; o ganho de seleção foi de 16,65\% para PTC e entre $-1,29 \%$ e $-7,60 \%$, nos demais caracteres; as progênies selecionadas conseguiram associar os valores desejados nos caracteres avaliados. As conclusões obtidas foram de que há elevada contribuição ambiental na manifestação fenotípica das progênies, sendo que as dimensões métricas dos frutos sofreram menores efeitos ambientais e maior efeito genético; há possibilidade de ganhos genéticos importantes aos programas de melhoramento genético da espécie utilizando-se os caracteres de forma simultânea, apesar dos valores obtidos terem sido baixos, principalmente devido à presença de correlações positivas, nas quais há preferência da redução do tamanho do fruto com aumento de produtividade.

Palavras-chave: Euterpe oleracea; região amazônica; melhoramento vegetal; variabilidade genética.

\section{ABSTRACT}

The objective of this article was to estimate the genetic variability and selection gain in the characters related with fruits in assai palms, 68 progenies collected in populations from Afuá city and planted in Amapá state were evaluated. The experiment was conducted in random blocks with two replications and four useful plants per plot. The following characters were evaluated: fruit longitudinal diameter (DLF), the fruit greatest transversal diameter (DTMA), the smallest fruit diameter (DTME); mass from one hundred fruits (P100) and, in bunches: total fruit mass (PTC). There are differences between progenies, denoting the possibility of selection gains. In general, the inheritabilities were medium or high for the characters, but always lower for PTC. The coefficient $\mathrm{CVg} / \mathrm{CVe}$ was favorable in DTMA and DTME and unfavorable to PTC; the

1 Engenheiro Agrônomo, Pesquisador da Empresa Brasileira de Pesquisa Agropecuária, Rod. JK, km 05, 2600, CEP 68903-419, Macapá (AP), Brasil. gilberto.yokomizo@embrapa.br

2 Engenheiro Florestal, Pesquisador da Empresa Brasileira de Pesquisa Agropecuária, Rod. JK, km 05, 2600, CEP 68903-419, Macapá (AP), Brasil. silas.mochiutti@embrapa.br

3 Engenheiro Florestal, Pesquisador da Empresa Brasileira de Pesquisa Agropecuária Oriental, Trav. Dr. Enéas Pinheiro, s/n, Caixa postal 48, Bairro Marco, CEP 66095-100, Belém (PA), Brasil. jose.queiroz@embrapa.br

4 Engenheiro Florestal, Rua Jovino Dinoá, 2085, CEP 68900-075, Macapá (AP), Brasil. reisgeorge@hotmail.com / rg_ap@hotmail.com

5 Tecnóloga Ambiental, Rod. Duque de Caxias, km 05, CEP 68906-720, Macapá (AP), Brasil. duada.ancelma@hotmail.com / ire.clei@bol.com.br 
correlations between characters were positive and significant, the selection gain was $16.65 \%$ for PTC and from $-1.29 \%$ to $-7.60 \%$ in the other characters; the selected progenies were able to associate the desired values in the evaluated characters. The obtained conclusions were that there is high environmental contribution in the phenotypic manifestation of the progenies once the fruit metric dimensions had lower environmental effects and higher genetic effect; there is possibility of genetic gains which are important to breeding programs of this species using the characters simultaneously, although the values had been low, mainly due to the positive correlation presence, where there is preference for reduced fruit size with productivity increase.

Keywords: Euterpe oleracea; Amazonian region; plant breeding; genetic variability.

\section{INTRODUÇÃO}

O açaizeiro (Euterpe oleracea Mart.) é uma espécie nativa da Região Amazônica, encontrada nas várzeas de estuário e que possui inestimável importância socioeconômica naquela região. O Estado do Pará, atualmente, é o maior produtor de frutos e o principal consumidor do suco denominado de "vinho de açár", com destaque pelas populações ribeirinhas (OLIVEIRA et al., 2002). A espécie pertence à família Arecaceae (QUEIROZ e MELÉM JÚNIOR, 2001; SOUSA e LORENZI, 2008). Caracteriza-se por ser perene, alógama e propagada quase que exclusivamente por sementes (JARDIM, 1991; OLIVEIRA et al., 2000). É considerada uma espécie semidomesticada ou em fase de domesticação (CLEMENT, 1992).

A polpa de seu fruto apresenta bom valor nutricional e constitui-se em uma das bases alimentares da dieta das populações dos Estados do Pará e Amapá. Na região Sul do Brasil, o consumo é crescente, em razão de ser um alimento de apelo ecológico combinado com sua característica energética (ROGEZ, 2000). Estas propriedades incrementaram seu consumo pelos esportistas e também, para a exportação, principalmente para os mercados com elevado poder aquisitivo como é o caso do Hemisfério Norte.

$\mathrm{Na}$ última estimativa do IBGE (2009), a produção nacional de açaí foi de 116 mil toneladas de frutos, com faturamento de R $\$ 160,5$ milhões. É interessante citar que $87,43 \%$ da produção está concentrada no Pará; $1,43 \%$, no Acre; $1,36 \%$, no Amazonas; $1,15 \%$, no Amapá e $8,17 \%$ no nordeste do Maranhão. A produção de frutos de açaí na região Norte é responsável por $91 \%$ da produção nacional. Entretanto, observa-se aumento considerável de consumo na região Sudeste do Brasil e em países da Europa, Estados Unidos, Japão e China o que exige aumento na produtividade desta espécie (SOUTO,
2001; SILVA, 2002).

Um aspecto relevante é que a Pesquisa de Orçamento Familiar, realizada pelo IBGE (2010), mostra que o consumo anual per capita de açaí no Estado do Amapá foi de 23,96 L e no Pará de 17,84 L. Ao se supor preço médio por litro em torno de R\$ 5,00 no Amapá em 2010, pode-se verificar que o açaí movimentou em torno $\mathrm{R} \$ 77,69$ milhões na economia estadual. Neste contexto, para se produzir 15,54 L, seriam necessárias cerca de 31.080 toneladas de frutos de açaí.

O principal programa de melhoramento genético do açaizeiro no Brasil é conduzido pela Embrapa Amazônia Oriental. Esse programa é considerado recente e os métodos de seleção empregados têm sido seleção fenotípica individual/ seleção massal e a seleção em teste de progênies. Como a espécie ainda é pouco melhorada, a seleção fenotípica tem sido a estratégia mais utilizada e consiste na escolha dos melhores indivíduos com base nos caracteres de produção de frutos, perfilhamento, precocidade de produção e estado fitossanitário das plantas (FARIAS NETO et al., 2005). Adicionalmente, ressalta-se que há existência de variabilidade genética entre populações e/ou progênies, o que permite seleção de materiais superiores para os caracteres de interesse (OLIVEIRA et al., 2000; FARIAS NETO et al., 2003; OHASHI e KAGEYAMA, 2004).

O crescimento da demanda interna e externa é, atualmente, um dos principais estimuladores do plantio do açaizeiro em larga escala, tanto para áreas de várzea quanto em terra firme (QUEIROZ e MOCHIUTTI, 2001). Isso porque o extrativismo não será capaz de atender a essas crescentes demandas. Entretanto, a expansão dos cultivos em terra firme, apresenta resultados altamente heterogêneos quanto à produtividade e qualidade dos frutos.

Do exposto, estudos no intuito de melhor caracterizar o germoplasma e para conhecer o 
comportamento da espécie devem ser conduzidos, pois fornecerão informações extremamente importantes em relação aos aspectos morfogenéticos para orientar os programas de melhoramento genético.

Informações sobre a produtividade de frutos do açaizeiro são bastante contraditórias (CALZAVARA, 1972; ROGEZ, 2000). Os principais motivos são: estimativas baseadas em açaizais nativos; em pomares estabelecidos com sementes de procedências desconhecidas e pronunciado efeito do ambiente; ausência de delineamento experimental e/ ou emprego de delineamento com pequeno número de repetições. Em virtude desses problemas, a produção estimada por planta tem variado de $0,1 \mathrm{~kg}$ e $50,9 \mathrm{~kg}$ de frutos/planta/ano (OLIVEIRA et al., 2000).

No momento existem poucos trabalhos avaliando a variabilidade e as correlações entre caracteres em açaí. Assim, infere-se que estudos no intuito de melhor caracterizar o germoplasma e para conhecer o comportamento da espécie devem ser conduzidos, permitindo a seleção de materiais superiores. Contudo, este procedimento não é fácil, pois muitas vezes os caracteres de importância, em sua maioria quantitativos, apresentam comportamento complexo, sofrem influência ambiental e por se inter-relacionarem, de tal forma que a seleção de um provoca uma série de mudanças em outros (CRUZ, 2001).

Para a obtenção de genótipos superiores, é necessária a reunião de uma série de atributos favoráveis que confiram melhor desempenho e satisfaçam as exigências do mercado. Com isso, a seleção baseada em uma ou poucas características mostra-se inadequada, conduzindo a um produto final superior apenas em relação aos caracteres selecionados (CRUZ e REGAZZI, 1997). Por isso, a seleção simultânea de um conjunto de caracteres de expressividade econômica aumenta a chance de êxito de um programa de melhoramento. Para tal, a teoria de índice de seleção permite combinar as múltiplas informações contidas na unidade experimental, o que possibilita a seleção com base em um complexo de características. Desse modo, o índice de seleção constitui-se em um caráter adicional, estabelecido pela combinação linear ótima de vários caracteres, que permite efetuar, com eficiência, a seleção simultânea (CRUZ e REGAZZI, 1997).

Neste contexto, objetivou-se avaliar a variabilidade genética entre progênies de açaizeiro, estimar correlações fenotípicas e, verificar a potencialidade das progênies a serem empregadas como material genético a ser utilizado nos cruzamentos em etapas futuras de melhoramento, por meio do índice de soma de postos proposto por Mulamba e Mock (1978).

\section{MATERIAL E MÉTODO}

\section{Caracterização do local}

Sementes de açaizeiro foram coletadas de 68 matrizes em populações existentes no município de Afuá, no Estado do Pará, no ano de 2000. Posteriormente, em 2001, foi implantado um teste de progênies em área de várzea no Campo Experimental de Mazagão, no município de Mazagão - AP. A área experimental tem coordenadas $00^{\circ} 02^{\prime} 33^{\prime \prime}$ de latitude sul e 51 15 '24" longitude oeste, com $17 \mathrm{~m}$ de altitude. O solo predominante é do tipo Glei Pouco Húmico de textura média, drenado e de média-alta fertilidade natural, com topografia plana e cobertura vegetal tipo capoeira. O clima caracteriza-se por ser do tipo tropical chuvoso (Ami), segundo classificação de Köppen. A precipitação média anual é de $2.300 \mathrm{~mm}$, concentrada entre os meses de janeiro a junho, com precipitação do mês mais seco de $10 \mathrm{~mm}$. A temperatura média do mês mais frio é superior a $22,5^{\circ} \mathrm{C}$, a temperatura média anual é de $28^{\circ} \mathrm{C}$ e umidade média do ar, $85 \%$.

O delineamento experimental utilizado foi blocos completos casualizados com duas repetições e quatro plantas úteis por parcela. O espaçamento entre plantas foi de $4 \mathrm{~m} \times 5 \mathrm{~m}$, totalizando 500 plantas/ha. Foram avaliados 100 frutos por cacho de cada planta, sendo que as avaliações foram realizadas até no máximo 24 horas pós-colheita.

Aos seis anos de idade, características de frutos maduros foram avaliadas nas 68 progênies.

\section{Caracteres avaliados}

Em concordância com nomenclatura proposta por Oliveira et al. (2006), foram avaliados os seguintes caracteres, com base na amostragem de 100 frutos do cacho coletados em 2008: massa (P100), em gramas; diâmetro longitudinal do fruto (DLF), medido do ponto de inserção dos restos florais (cálice e corola) até o vestígio do estigma, em centímetros; maior diâmetro transversal do fruto (DTMA), em centímetros; menor diâmetro transversal do fruto (DTME), em centímetros. Adicionalmente foi também mensurado a massa 
total de frutos do cacho (PTC), em quilogramas.

\section{Análises estatísticas}

A análise de variância foi realizada com auxílio do programa SAS, versão 8.1 (SAS INSTITUTE, 2000). Os procedimentos estatísticos foram os apresentados por Vencovsky e Barriga (1992), cujo modelo matemático adotado foi: $\mathrm{Y}_{\mathrm{ijk}}$ $=\mathrm{m}+\mathrm{G}_{\mathrm{i}}+\mathrm{P}_{\mathrm{j}}+\mathrm{B}_{\mathrm{k}}+\mathrm{e}_{\mathrm{ijk}}$; em que: $\mathrm{Y}_{\mathrm{ij}}$ é o valor fenotípico médio do caráter $Y$ medido no material genético i na planta $\mathrm{j}$ e na repetição $\mathrm{k}$; $\mathrm{m}$ é a média geral paramétrica dos dados de efeito fixo; $G_{i}$ é o efeito do $i$-ésimo genótipo, de efeito aleatório; $\mathrm{P}_{\mathrm{j}} \mathrm{e}$ $o$ efeito da $j$-ésima planta dentro da progênie $\mathrm{i} ; \mathrm{B}_{\mathrm{k}}$ é o efeito da $k$-ésima repetição; e $\mathrm{e}_{\mathrm{ijk}}$ é o erro médio associado à observação $\mathrm{Y}_{\mathrm{ijk}}$, de efeito aleatório. As esperanças dos quadrados médios são apresentadas na Tabela 1.

O efeito de progênies foi considerado aleatório em virtude dos materiais terem sido obtidos por meio de polinização aberta.

As correlações de Pearson $\left(r_{p}\right)$ foram realizadas com auxílio do programa computacional GENES (CRUZ, 2001), segundo a equação:

$$
r_{p(X Y)}=\frac{\operatorname{COV}_{(X Y)}}{\sqrt{V_{(x)} V_{(Y)}}}
$$

Sendo que: $\mathrm{r}_{\mathbf{P}(\mathbf{X Y})}$ é a correlação de Pearson entre os caracteres x e y; $\mathrm{COV}_{(\mathrm{XY})}$ é o produto médio de tratamentos para os caracteres $\mathrm{x}$ e y envolvidos e $V_{(\mathbf{X})}$ e $V_{(\mathbf{Y})}$ são as variâncias de progênies para os caracteres $\mathrm{x}$ e $\mathrm{y}$, respectivamente.

Foi estimado o ganho de seleção de $20 \%$ das progênies com o índice baseado em soma de "ranks" (MULAMBA e MOCK, 1978) que consiste em classificar os genótipos em relação a cada um dos caracteres, em ordem favorável ao melhoramento. A seguir, são somadas as ordens de cada material resultando no índice de seleção, em que $\mathrm{I}=\mathrm{r}_{1}+\mathrm{r}_{2}+\ldots+\mathrm{r}_{\mathrm{n}}$, sendo que I é o valor do índice para determinado indivíduo ou progênie; $r_{j}$ é a classificação de uma progênie em relação ao j-ésimo caráter e $\mathrm{n}$ é o número de caracteres considerado no índice. Por meio deste índice, há possibilidade de se atribuir diferentes pesos aos caracteres avaliados, conforme sua importância. Assim, tem-se que $\mathrm{I}=$ $\mathrm{p}_{1} \mathrm{r}_{1}+\mathrm{p}_{2} \mathrm{r}_{2}+\ldots+\mathrm{p}_{\mathrm{n}} \mathrm{r}_{\mathrm{n}}$, em que $\mathrm{p}_{\mathrm{j}}$ é o peso atribuído pelo usuário ao j-ésimo caráter. No presente caso, foi atribuído peso 5 para PTC, 2 para P100 e 1 para os demais caracteres.

\section{RESULTADOS E DISCUSSÃO}

Houve diferenças significativas a $1 \%$ entre as progênies em todos os caracteres avaliados. Assim, pode-se inferir que há possibilidade de seleção de genótipos superiores (Tabela 1). Esses resultados estão em consonância com aqueles observados por Oliveira et al. (2007) e com Oliveira e Fernandes (2001). Neste último, somente houve divergência quanto ao PTC. Na análise do efeito de plantas dentro de repetições e das repetições não foram observadas diferenças significativas nos caracteres avaliados.

Nos caracteres relacionados às dimensões de frutos (DLF, DTMA, DTME), as médias apresentaram-se muito próximas, o que indica que o formato predominante dos frutos é arredondado. Caso o caráter DLF apresentasse médias superiores, os frutos tenderiam a ser alongados. Ao passo que se as médias superiores fossem para DTMA ou DTME, os frutos tenderiam a ser achatados, como encontrado por Oliveira et al. (2007).

Para o caráter PTC, a média foi de baixa magnitude quando comparada aos resultados de Oliveira e Fernandes (2001) e Oliveira et al. (2007), com $2,44 \mathrm{~kg}$ e $2,53 \mathrm{~kg}$, respectivamente. Isso está relacionado à idade e aos aspectos nutricionais das plantas durante a formação dos cachos. É importante observar que há conhecimento empírico da relação entre o PTC com a idade das touceiras e disponibilidade natural de fertilidade dos solos de várzea. A falta de manejo das plantas invasoras, principalmente do tipo trepadoras, no começo do desenvolvimento das plantas, pode ser responsável pelos valores consideravelmente menores.

Os caracteres DLF, DTMA, DTME e P100 apresentaram estimativas de variâncias genotípicas superiores às residuais, o que pode indicar predominância dos efeitos genéticos, semelhante ao observado por Farias Neto et al. (2008). Entretanto, deve-se ressaltar que a variância genotípica se encontra inflacionada pelo efeito da interação progênies $\mathrm{x}$ ambientes em virtude de a avaliação ter sido conduzida em um único ambiente (VENCOVSKY e BARRIGA, 1992).

Para PTC, a variância residual foi superior à genotípica, distinta da observada por Farias Neto et al. (2008). Do exposto, as progênies parecem ter respostas diferenciadas quanto às variações de quantidade de nutrientes sedimentados, umidade do solo e temperaturas elevadas. Esses fatores são fundamentais ao adequado desempenho fisiológico 
TABELA 1: Análise de variância para cinco caracteres avaliados em frutos para plantas individuais de 68 progênies de açaizeiro (Euterpe oleracea). Macapá - AP, 2008.

TABLE 1: Analysis of variance summarized for five characters evaluated at the fruits in individual plants from 68 progenies of the assai palms (Euterpe oleracea). Macapá, AP state, 2008.

\begin{tabular}{|c|c|c|c|c|c|c|c|}
\hline \multirow{2}{*}{ FV } & \multirow{2}{*}{ GL } & \multicolumn{6}{|c|}{ QM } \\
\hline & & DLF & DTMA & DTME & PTC & P100 & EQM \\
\hline Blocos & 1 & $0,012^{\mathrm{ns}}$ & $0,005^{\mathrm{ns}}$ & $0,007^{\mathrm{ns}}$ & $0,327^{\mathrm{ns}}$ & $325,915^{\mathrm{ns}}$ & $\sigma_{d}^{2}+$ j. $\sigma_{e}^{2}+i j . \sigma_{b}^{2}$ \\
\hline Progênies & 67 & $0,009 * *$ & $0,016^{* *}$ & $0,011 * *$ & $1,120 * *$ & $1052,049 * *$ & $\sigma_{d}^{2}+j \cdot \sigma_{e}^{2}+j k \cdot \sigma_{p}^{2}$ \\
\hline Resíduo & 67 & 0,004 & 0,004 & 0,003 & 0,943 & 408,015 & $\sigma_{d}^{2}+j \cdot \sigma_{e}^{2}$ \\
\hline Dentro & 408 & $0,002^{\text {ns }}$ & $0,003^{\text {ns }}$ & $0,003^{\mathrm{ns}}$ & $0,765^{\mathrm{ns}}$ & $126,756^{\mathrm{ns}}$ & $\sigma_{d}^{2}$ \\
\hline Total & 543 & & & & & & \\
\hline Médias & & 1,110 & 1,288 & 1,147 & 1,349 & 117,154 & \\
\hline
\end{tabular}

Em que: DLF = diâmetro longitudinal do fruto, em centímetros; DTMA = maior diâmetro transversal do fruto, em centímetros; DTME = menor diâmetro transversal do fruto, em centímetros; PTC = peso total de frutos do cacho, em quilogramas; P100 = peso de cem frutos, em gramas; $\sigma_{\mathrm{P}}^{2}=$ variância entre plantas dentro de blocos; $\sigma_{\mathrm{e}}^{2}=$ variância do resíduo; $\sigma_{\mathrm{b}}^{2}=$ variância dos blocos; $\sigma_{\mathrm{p}}^{2}$ : variância das progênies; $\mathrm{i}, \mathrm{j}$ e $\mathrm{k}$, números de progênies, de plantas dentro de blocos e blocos, respectivamente. ns não significativo e ${ }^{* *}$ significativo a $1 \%$ para o teste $\mathrm{F}$.

da planta e da formação dos frutos. Do exposto, há urgência na priorização de pesquisas sobre absorção de nutrientes do solo e fisiologia da espécie.

De modo geral, as estimativas de $\mathrm{CVe}$ foram baixas (Tabela 2), semelhantes ao obtido por Oliveira e Fernandes (2001) e Oliveira et al. (2007). Assim, houve rigor experimental, exceto para o caráter P100. O CVg foi superior aos CVe para os caracteres DLF, DTMA, DTME e P100, o que indica variabilidade disponível para seleção. Resultados similares foram encontrados por Oliveira et al. (2007) e Teixeira et al. (2008).

$\mathrm{Na}$ seleção é necessária facilidade na diferenciação de materiais superiores entre as progênies avaliadas. De forma preliminar, isso pode ser observado pela relação entre $\mathrm{CVg}$ e CVe. Valores próximos ou acima da unidade indicam presença de variabilidade suficiente para seleção, com possibilidade ganhos (VENCOVSKY e BARRIGA, 1992).

Os resultados de $\mathrm{CVg} / \mathrm{CVe}$ indicam que DTMA e DTME apresentaram os melhores índices, com maior contribuição genética na manifestação fenotípica. Para o caráter PTC, houve maior contribuição dos fatores ambientais, o que exige maior rigor na seleção. Salienta-se que Oliveira e Fernandes (2001), Farias Neto et al. (2008) e Teixeira et al. (2008) obtiveram resultados divergentes aos obtidos neste trabalho.

Elevadas estimativas de correlações fenotípicas foram observadas entre DLF, DTMA, DTME e P100 (Tabela 3). Assim, há possibilidade de adotar aquele menos oneroso ou de menor tempo de obtenção, com seleção dos demais de forma indireta. Neste caso, recomenda-se o uso do P100 que necessita apenas o uso de balança. Para os outros há necessidade de mensuração individual dos frutos com paquímetro, os quais demandam mais tempo e trabalho.

As estimativas de correlação entre PTC e demais caracteres foram baixas, semelhantes ao observado por Farias Neto et al. (2008). Isso porque para PTC, há maior contribuição dos fatores ambientais na variância fenotípica. Foi observado valor positivo de correlação entre tamanho dos cachos e frutos. Entretanto, são desejados frutos menores. Esse fato pode dificultar a seleção dos melhores materiais, pois há tendência nas progênies de maiores produções estarem associadas aos frutos maiores.

Menor tamanho de frutos é preferido pelos comerciantes, isso porque há maior rendimento da bebida "açaí" nas máquinas de processamento (FARIAS NETO et al., 2011).

A seleção das melhores progênies foi feita com base na soma de postos. Como critério de seleção foi assumido que quanto menores os valores de DLF, DTMA, DTME e P100 e maiores de PTC melhor. Com isso, conseguiu-se obter ganhos desejados de menor intensidade para os caracteres 
TABELA 2: Parâmetros genéticos e fenotípicos de cinco caracteres avaliados em frutos para plantas individuais de 68 progênies de açaizeiro (Euterpe oleracea). Macapá - AP, 2008.

TABLE 2: Phenotypic and Genotypic parameters for five characters evaluated at the fruits in individual plants from 68 progenies of the assai palms (Euterpe oleracea). Macapá, AP state, 2008.

\begin{tabular}{lccccc}
\hline \multicolumn{1}{c}{ Parâmetros } & DLF & DTMA & DTME & PTC & P100 \\
\hline$\sigma_{\text {fenotipica }}^{2}$ & 0,0011 & 0,0020 & 0,0013 & 0,1399 & 131,5061 \\
$\sigma_{\text {residual }}^{2}$ & 0,0005 & 0,0003 & 0,0001 & 0,0447 & 70,3148 \\
$\sigma_{\text {genética aditiva individual }}^{2}$ & 0,0005 & 0,0015 & 0,0009 & 0,0220 & 80,5042 \\
$\mathrm{CVg}(\%)$ & 0,0482 & 0,1181 & 0,0773 & 1,6309 & 68,7189 \\
$\mathrm{CVe}(\%)$ & 0,0449 & 0,0221 & 0,0116 & 3,3108 & 60,02120 \\
$\mathrm{CVg} / \mathrm{CVe}$ & 1,0724 & 5,3531 & 6,6374 & 0,4926 & 1,1449 \\
\hline
\end{tabular}

Em que: DLF = diâmetro longitudinal do fruto, em centímetros; DTMA = maior diâmetro transversal do fruto, em centímetros; DTME = menor diâmetro transversal do fruto, em centímetros; PTC = peso total de frutos do cacho, em quilogramas; $\mathrm{P} 100$ = peso de cem frutos, em gramas; $\mathrm{CVg}(\%)=$ coeficiente de variação genotípica em porcentagem; $\mathrm{CVe}(\%)=$ coeficiente de variação ambiental em porcentagem; $\mathrm{CVg} / \mathrm{CVe}=$ relação entre coeficiente de variação genotípica pelo coeficiente de variação ambiental.

TABELA 3: Estimativas de correlação fenotípicas para cinco caracteres avaliados em frutos para plantas individuais de 68 progênies de açaizeiro (Euterpe oleracea). Macapá - AP, 2008.

TABLE 3: Estimates of phenotypic correlation for five traits evaluated in fruits for individual plants from 68 progenies of the assai palms (Euterpe oleracea). Macapá, AP state, 2008.

\begin{tabular}{ccccc}
\hline & DTMA & DTME & PTC & P100 \\
\hline DLF & $0,7875^{* *}$ & $0,7981^{* *}$ & $0,2712^{* *}$ & $0,7807^{* *}$ \\
DTMA & & $0,8735^{* *}$ & $0,2061^{* *}$ & $0,8717^{* *}$ \\
DTME & & $0,2148^{* *}$ & $0,8522^{* *}$ \\
PTC & & & $0,3106^{*}$ \\
\hline
\end{tabular}

Em que: DLF = diâmetro longitudinal do fruto, em centímetros; DTMA = maior diâmetro transversal do fruto, em centímetros; DTME = menor diâmetro transversal do fruto, em centímetros; PTC = peso total de frutos do cacho, em quilogramas; P100 = peso de cem frutos, em gramas. ${ }^{* *}$ significativo a $1 \%$ para o teste $\mathrm{t} ;{ }^{*}$ significativo a $5 \%$ para o teste t.

relacionados a dimensões dos frutos, porém, em maior intensidade para P100 que seria a alternativa mais fácil de avaliação do tamanho dos frutos, associado ao maior ganho positivo para PTC, acima de $15 \%$, um valor que pode ser considerado muito bom para ganho em apenas um processo de seleção.

As herdabilidades na média de progênies foram de média magnitude para DLF, DTME e PTC e altas para DTMA e P100, segundo os limites propostos por Resende (2002). Os valores demonstram ser possível manter os ganhos estimados com a seleção na média de progênies.

Na seleção das $20 \%$ melhores progênies, foram selecionadas 14 progênies. As estimativas foram inferiores aquelas de Farias Neto et al. (2011). Entretanto, no trabalho citado, não foram incluídos os caracteres de dimensão dos frutos, aspecto fundamental de mercado. Por outro lado, em estudo com maior número de caracteres, o ganho obtido para PTC e P100 foram superiores (TEIXEIRA et al., 2012). Essas diferenças indicam que a eficiência de seleção é inerente à população.

\section{CONCLUSÕES}

Os caracteres relativos a dimensões métricas dos frutos possuem maior contribuição genética em comparação ao relacionado a produtividade total de frutos.

Grande parcela da expressão fenotípica dos caracteres se dá devido à grande influência de fatores ambientais sobre os mesmos em detrimento 
da genética, o que pode dificultar o processo de seleção de forma generalista, devendo-se, portanto, sempre avaliar as progênies quando instaladas em novas condições ambientais.
Correlações positivas entre tamanho dos frutos e produtividade total do cacho podem dificultar a seleção simultânea entre estes caracteres, já que são preferenciais à redução do tamanho do

TABELA 4: Estimativa de ganhos genéticos preditos pelo índice soma de postos na seleção de progênies superiores de açaizeiros. Macapá - AP, 2008.

TABLE 4: Estimation of the genetic gain predicted by using the index based on the rank sum to selection process of the superior assai progenies. Macapá, AP state, 2008.

\begin{tabular}{lccrrrrr}
\hline \multicolumn{1}{c}{ Caráter } & Peso & Sentido & \multicolumn{1}{c}{ Xo } & \multicolumn{1}{c}{ Xs } & $\mathrm{h}^{2}{ }_{\mathrm{mp}}$ & \multicolumn{1}{c}{$\mathrm{GS}$} & $\mathrm{GS} \%$ \\
\hline DLF & 1 & Diminuir & 1,114 & 1,091 & 64,077 & $-0,014$ & $-1,29$ \\
DTMA & 1 & Diminuir & 1,286 & 1,243 & 80,784 & $-0,035$ & $-2,72$ \\
DTME & 1 & Diminuir & 1,146 & 1,113 & 69,693 & $-0,023$ & $-2,04$ \\
PTC & 5 & Aumentar & 1353,486 & 1832,967 & 46,997 & 225,340 & 16,65 \\
P100 & 2 & Diminuir & 116,776 & 105,018 & 75,485 & $-8,875$ & $-7,60$ \\
\hline
\end{tabular}

Em que: DLF = diâmetro longitudinal do fruto, em centímetros; DTMA = maior diâmetro transversal do fruto, em centímetros; DTME = menor diâmetro transversal do fruto, em centímetros; $\mathrm{PTC}=$ peso total de frutos do cacho, em quilogramas; P100 = peso de cem frutos, em gramas; Peso = valor adotado seguindo a importância dos caracteres para seleção; $\mathrm{Xo}=$ média das progênies na população inicial; $\mathrm{Xs}=$ média das progênies após a seleção genética; $\mathrm{h}^{2}{ }_{\mathrm{mp}}$ = herdabilidade na médias de progênies; GS = ganho de seleção em valor absoluto; GS\% = ganho de seleção, em porcentagem.

TABELA 5: Médias para cinco caracteres das progênies selecionadas de açaizeiro utilizando-se o índice baseado em soma de postos com base principalmente na produção de cachos. Macapá - AP, 2008.

TABLE 5: Averages for five characters of the selected assai progenies using the index based on the rank sum based primarily on total weight of the bunches. Macapá, AP state, 2008.

\begin{tabular}{ccccccc}
\hline \multirow{2}{*}{ Classificação } & \multirow{2}{*}{ Progênies } & \multicolumn{5}{c}{ Médias } \\
\cline { 3 - 7 } & & DLF $(\mathrm{cm})$ & DTMA $(\mathrm{cm})$ & DTME $(\mathrm{cm})$ & PTC $(\mathrm{Kg})$ & P100 $(\mathrm{g})$ \\
\hline 1 & 14 & 1,06 & 1,18 & 1,07 & 1,97 & 90,63 \\
2 & 17 & 1,12 & 1,23 & 1,1 & 1,84 & 103,23 \\
3 & 33 & 1,08 & 1,25 & 1,11 & 1,89 & 105,79 \\
4 & 8 & 1,11 & 1,27 & 1,12 & 2,52 & 109,63 \\
5 & 57 & 1,06 & 1,21 & 1,09 & 1,49 & 99,61 \\
6 & 48 & 1,1 & 1,24 & 1,12 & 1,71 & 103,27 \\
7 & 35 & 1,03 & 1,18 & 1,06 & 1,44 & 86,67 \\
8 & 50 & 1,13 & 1,28 & 1,15 & 2,32 & 114,97 \\
9 & 5 & 1,09 & 1,28 & 1,14 & 1,76 & 109,06 \\
10 & 15 & 1,12 & 1,29 & 1,15 & 2,19 & 114,8 \\
11 & 7 & 1,11 & 1,25 & 1,13 & 1,67 & 107,49 \\
12 & 6 & 1,13 & 1,3 & 1,16 & 2,20 & 121,36 \\
13 & 37 & 1,09 & 1,25 & 1,12 & 1,45 & 104,05 \\
14 & 36 & 1,09 & 1,21 & 1,09 & 1,21 & 99,73 \\
\hline
\end{tabular}

Em que: DLF = diâmetro longitudinal do fruto, em centímetros; DTMA = maior diâmetro transversal do fruto, em centímetros; DTME = menor diâmetro transversal do fruto, em centímetros; $\mathrm{PTC}=$ peso total de frutos do cacho, em quilogramas; $\mathrm{P} 100=$ peso de cem frutos, em gramas. 
fruto com aumento de produtividade.

Há possibilidade de ganhos genéticos importantes nos programas de melhoramento genético da espécie com base na seleção usandose vários índices em conjunto, contudo devido à presença de correlações positivas os valores obtidos são baixos.

Devido à inexistência de processos de seleção nos materiais avaliados torna-se possível a seleção de progênies que associem dimensões dos caracteres adequados.

\section{AGRADECIMENTOS}

Os autores agradecem a SETEC/CNPq pelas bolsas de estudos concedidas aos estagiários.

\section{REFERÊNCIAS BIBLIOGRÁFICAS}

CLEMENT, C.R. Domesticated palms. Principes, Lawrence, v. 36, n. 2, p. 70-78, 1992.

CRUZ, C.D. GENES: Programa para análise e processamento de dados baseado em modelos de genética e estatística experimental: versão 2001.0.0. Viçosa: UFV, 2001. 247 p.

CRUZ, C.D.; REGAZZI, A.J. Modelos biométricos aplicados ao melhoramento genético. Viçosa: UFV, 1997. $390 \mathrm{p}$.

FARIAS NETO, J. T. et al. Estimativas de parâmetros genéticos e ganho de seleção em progênies de polinização aberta de açaizeiro. Revista Brasileira de Fruticultura, Jaboticabal, v. 30, p. 1051-1056, 2008.

FARIAS NETO, J.T. et al. Variabilidade genética entre duas procedências de açaizeiro (Euterpe oleracea Martus). Boletim de Pesquisa Florestal, Colombo, v. 46, p. 97-104, 2003.

FARIAS NETO, J.T. de.; RESENDE, M.D.V. de.; OLIVEIRA, M. do S.P. de. Seleção simultânea em progênies de açaizeiro irrigado para produção e peso de fruto. Revista Brasileira de Fruticultura, Jaboticabal, v. 33, p. 532-539, 2011.

JARDIM, M.A.G. Aspectos da biologia reprodutiva de uma população natural de açaizeiro (Euterpe oleracea Mart.) no Estuário amazônico. 1991. 90 f. Dissertação (Mestrado em Agronomia), Escola Superior de Agricultura de Luiz de Queiroz, Universidade de São Paulo - SP, 1991.

MULAMBA, N.N.; MOCK, J.J. Improvement of yield potential of the Eto Blanco maize (Zea mays L.) population by breeding for plant traits. Egyptian
Journal of Genetics and Cytology, Alexandria, v. 7, p. 40-57, 1978.

OHASHI, S.T.; KAGEYAMA, P.Y. Variabilidade genética entre populações de açaizeiro (Euterpe oleracea Mart.) do estuário amazônico. In: MOURÃO, L.; JARDIM, M.A.; GROSSMANN, M. (ed.). Açaí: possibilidade e limites em processos de desenvolvimento sustentável no estuário amazônico. Belém: CEJUP. 2004. p.11-26.

OLIVEIRA, M. do S.P. de, FERREIRA, D.F.; SANTOS, J.B. Divergência genética entre acessos de açaizeiro fundamentada em descritores morfoagronômicos. Pesquisa Agropecuária Brasileira, Brasília, v. 42, n. 4, p. 501-506, 2007.

OLIVEIRA, M. do S.P. de. et al. Cultivo do açaizeiro visando a produção de frutos. Belém: Embrapa Amazônia Oriental, 2002. 51 p. (Embrapa Amazônia Oriental. Circular técnica, 26).

OLIVEIRA, M. do S.P. de; FERNANDES, G.L.C. Repetibilidade de caracteres do cacho de açaizeiro nas condições de Belém-PA. Revista Brasileira de Fruticultura, Jaboticabal, v. 23, n. 3, p. 613-616, 2001.

OLIVEIRA, M. do S.P. de; FERREIRA, D.F.; SANTOS, J.B. Seleção de descritores para caracterização de germoplasma de açaizeiro para produção de frutos. Pesquisa Agropecuária Brasileira, Brasília, v. 41, n. 7, p. 1133-1140, 2006. OLIVEIRA, M. do S.P. de. et al. Correlações fenotípicas entre caracteres vegetativos e de produção de frutos em açaizeiro. Revista Brasileira de Fruticultura, Jaboticabal, v. 22, p. 1-5, 2000.

PEDROZO, C.A. et al. Eficiência de índices de seleção utilizando a metodologia REML/BLUP no melhoramento da cana-de-açúcar. Scientia Agraria, Curitiba, v. 10, p. 31-36, 2009.

PIMENTEL GOMES, F. Curso de estatística experimental. $15^{\mathrm{a}}$ ed. Piracicaba: Fealq, 2009. 451p QUEIROZ, J.A.L.; MOCHIUTTI, S. Plantio de açaizeiros. Macapá: Embrapa Amapá, 2001. 8 p. (Embrapa Amapá. Comunicado técnico, 55).

RAMALHO, M.A.P.; SANTOS, J.B.; PINTO, C.A.B.P. Genética na Agropecuária. $4^{a}$ ed., Lavras: UFLA, 2008. $463 \mathrm{p}$.

RESENDE, M.D.V. de. Genética Biométrica e estatística no melhoramento de plantas perenes. Brasília: Embrapa Informação Tecnologia, 2002. $975 \mathrm{p}$.

ROGEZ, H. Açaí: preparo, composição e melhoramento da conservação. Belém: Edufpa, 2000. 313 p.

SAS INSTITUTE SAS language and procedures: 
usage. Version 8.1. North Caroline, NC: SAS Sociedade Brasileira de Fruticultura, Institute Inc., 2000. 1 CD-ROM. 2008. p.1-5.

TEIXEIRA, D.H.L.; OLIVEIRA, M.S.P. de.; TEIXEIRA, D.H.L.; OLIVEIRA, M. do S.P. PEDROSO, A.J.S. Estimativas de parâmetros de.; GONÇALVES, F.M.A. Índices de seleção genéticos e fenotípicos em progênies de meio- no aprimoramento simultâneo dos componentes irmãos de açaizeiro para caracteres de produção de da produção de frutos em açaizeiro. Pesquisa frutos em vários anos de colheita. In: CONGRESSO Agropecuária Brasileira, Brasília, v. 47, BRASILEIRO DE FRUTICULTURA, 20., p. 247-243, 2012.

ANNUALMEETING OFTHE INTERAMERICAN VENCOVSKY， R.; BARRIGA，P. Genética SOCIETY FOR TROPICAL HORTICULTURE, biométrica no fitomelhoramento. Ribeirão Preto: 54., 2008, Vitória. Anais... Vitória: INCAPER: SBG, 1992. 486 p. 